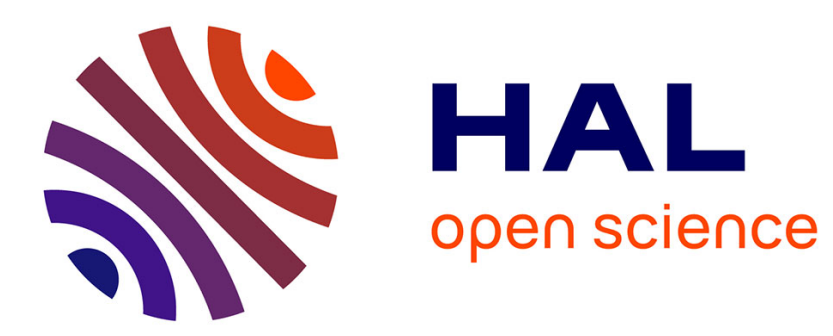

\title{
Control of the boost DC-AC converter with RL load by energy shaping
}

\author{
Carolina Albea-Sanchez, Francisco Gordillo
}

\section{To cite this version:}

Carolina Albea-Sanchez, Francisco Gordillo. Control of the boost DC-AC converter with RL load by energy shaping. CDC 2007 - 46th IEEE Conference on Decision and Control, Dec 2007, New Orleans, United States. pp.2417-2422. hal-00257261

\section{HAL Id: hal-00257261 \\ https://hal.science/hal-00257261}

Submitted on 18 Feb 2008

HAL is a multi-disciplinary open access archive for the deposit and dissemination of scientific research documents, whether they are published or not. The documents may come from teaching and research institutions in France or abroad, or from public or private research centers.
L'archive ouverte pluridisciplinaire HAL, est destinée au dépôt et à la diffusion de documents scientifiques de niveau recherche, publiés ou non, émanant des établissements d'enseignement et de recherche français ou étrangers, des laboratoires publics ou privés. 


\title{
Control of the Boost DC-AC Converter with RL Load by Energy Shaping
}

\author{
Carolina Albea and Francisco Gordillo
}

\begin{abstract}
In this paper a control strategy based on Energy Shaping is designed for the nonlinear boost DC-AC converter with no-resistive load. This approach does not need to use any reference signal. A Phase-Locked Loop is added to the control law in order to achieve synchronization between the two parts of the circuit, which is necessary to obtain the desired output voltage. It is also shown that this idea is also valid for synchronization with the network. The resultant control laws are tested by means of simulations.
\end{abstract}

\section{INTRODUCTION}

Boost DC-AC inverters are novel converters, whose main advantage is to achieve an output voltage higher than the input one. The control of these converters is usually accomplished tracking a reference signal. The use of this external signal makes the closed-loop control system to be non-autonomous and thus, making its analysis involved, as it can be shown in [1], [2], [3].

In [4] a new approach for obtaining a control law for electronics converters based on Energy Shaping was presented. The approach is focused on finding a control strategy that generates a stable limit cycle with given amplitude and frequency for which voltages and currents present a sinusoidal behavior with pre-specified phase shift. In this way the generation of alternating current will be accomplished without the necessity of introducing any external reference signal. The generation of limit cycles for producing self-oscillations has been successfully applied to electro-mechanical systems [5], [6], [7] as well as some applications to electronics converters are [8], [4], [9].

In [9] a control strategy was designed for the boost inverter using Energy Shaping for known resistive load. A phase-lock loop (PLL) was necessary for the correct operation of the circuit as well as for synchronization with the electrical grid. Subsequently, such result was extended to the case of unknown load using an adaptation mechanism, [10].

This paper considers the same problem when the load is not purely resistive but it is inductive as is usually the case in industrial applications. This problem was studied in [3], [11], [2] but using external signals in order to control the system. In this work, the approach based on

This work was not supported by any organization

C. Albea and F. Gordillo are with Departamento de Ingeniería de Sistemas y Automática, University of Seville, Camino de los Descubrimientos s/n. Sevilla-41092. Spain calbea@cartuja.us.es, gordillo@esi.us.es
Energy Shaping and there is not necessity of introducing any external signal. The problem of synchronization with the electrical network is also solved. The resultant controllers are checked by means of simulations.

The rest of the paper is organized as follows. In Sect. II the general ideal of generation of oscillating behavior by the generation of a limit cycle through Energy Shaping is presented. The boost inverter is described in Sect. III. Section IV states the problem, which is solved in Sect. V. Synchronization with the electrical network is shown in Sect. VI. Conclusions are drawn in Sect. VII.

\section{Generation of Oscillations by Energy SHAPING}

In power electronic converters with $\mathrm{AC}$ output the control objective can be seen as the generation of a stable limit cycle with given amplitude and frequency for which voltages and currents present a sinusoidal behavior with pre-specified phase shift. If a control law is able to produce such limit cycle, the generation of alternating current will be accomplished without the necessity of introducing any reference signal. For this, a target system may be defined and by matching its equations and the system equations a control law can be obtained. In order to define the target system consider the following energylike function

$$
H_{0}\left(\zeta_{1}, \zeta_{2}\right)=\frac{\omega}{4} \Gamma^{2}\left(\zeta_{1}, \zeta_{2}\right)
$$

with $\Gamma\left(\zeta_{1}, \zeta_{2}\right)=\omega^{2}\left(\zeta_{1}-\zeta_{10}\right)^{2}+\left(\zeta_{2}-\zeta_{20}\right)^{2}-\mu$. Parameters $\omega, \zeta_{10}, \zeta_{20}$ and $\mu>0$ should be chosen so that the closed curve $\Gamma\left(\zeta_{1}, \zeta_{2}\right)=0$ defines the desired behavior. This curve is an ellipse centered at the point $\left(\zeta_{10}, \zeta_{20}\right)$. We can define a dynamical system such that this closed curve is its limit set. This can be reached adopting $H_{0}$ as a Hamiltonian function, and defining the dynamical system $(3)-(4)$

$$
\left[\begin{array}{c}
\dot{\zeta}_{1} \\
\dot{\zeta}_{2}
\end{array}\right]=\left[\begin{array}{cc}
-k_{a_{1}} & \frac{1}{\Gamma} \\
-\frac{1}{\Gamma} & -k_{a_{2}}
\end{array}\right]\left[\begin{array}{c}
D_{\zeta_{1}} H_{0} \\
D_{\zeta_{2}} H_{0}
\end{array}\right]
$$

resulting

$$
\begin{aligned}
& \dot{\zeta}_{1}=\left(\zeta_{2}-\zeta_{20}\right)-k_{a_{1}} \omega^{2}\left(\zeta_{1}-\zeta_{10}\right) \Gamma \\
& \dot{\zeta}_{2}=-\omega^{2}\left(\zeta_{1}-\zeta_{10}\right)-k_{a_{2}}\left(\zeta_{2}-\zeta_{20}\right) \Gamma
\end{aligned}
$$

Noticing that

$$
\dot{H}_{0}=-\Gamma^{2}\left(k_{a_{1}} \omega^{4}\left(\zeta_{1}-\zeta_{10}\right)^{2}+k_{a_{2}}\left(\zeta_{2}-\zeta_{20}\right)^{2}\right) \leq 0
$$


and using LaSalle invariance principle it can be seen that for all initial conditions except the origin the trajectories of the system tend to the curve $\Gamma\left(\zeta_{1}, \zeta_{2}\right)=0$.

The behavior of this target system corresponds to the sinusoidal behavior that it is desired of a DC-AC converter. Constants $\omega, \zeta_{10}, \zeta_{20}$ and $\mu$ are design parameters for the frequency bias and amplitude of the desired behavior while $k_{a_{1}}$ and $k_{a_{2}}$ define the speed of the transient response.

\section{Boost DC-AC Converter Model}

The boost inverter is specially interesting because it generates an $\mathrm{AC}$ output voltage larger than the $\mathrm{DC}$ input one. It is made up of two DC-DC converters and a load connected differentially across them, Fig. 1. In [9], the load was resistive, in this paper we are going to use an RL load. Each converter produces a DC-biased sine wave output, $V_{1}$ and $V_{2}$, so that each source generates an unipolar voltage. The circuit implementation is shown in Fig. 2.

Voltages $V_{1}$ and $V_{2}$ should present a phase shift equal to $180^{\circ}$, which maximizes the voltage excursion across the RL load [1] Fig. 3.

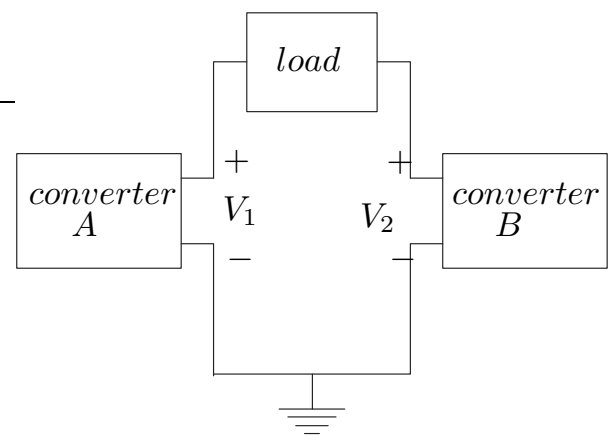

Fig. 1. Basic representation of the boost inverter.

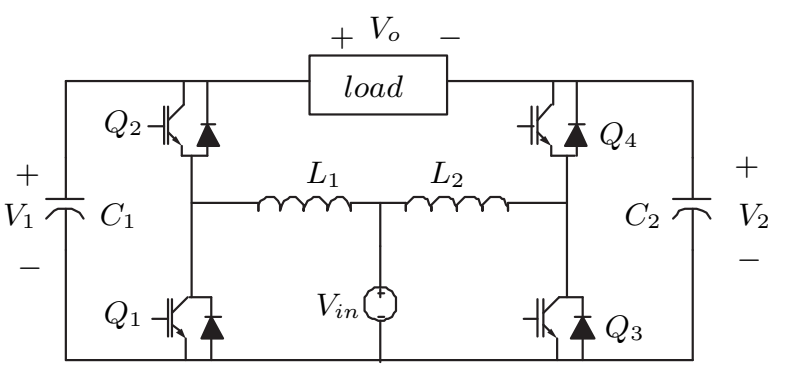

Fig. 2. Ideal boost DC-AC converter.

The boost DC-AC converter can be simplified as shown in Fig. 4. This simplification lets see clearer the bidirectional current of each boost DC-DC converter.

In order to make easier the studies, we will use this simplification for obtaining the control law, and then we will extrapolate these results to the full converter as it was done in [9], [10].

It is here assumed that
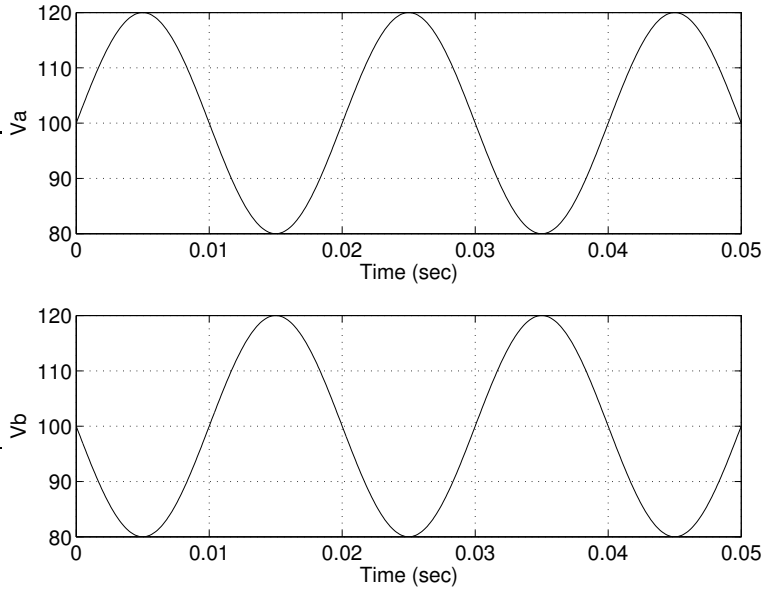

Fig. 3. Ideal output voltages of each boost converter.

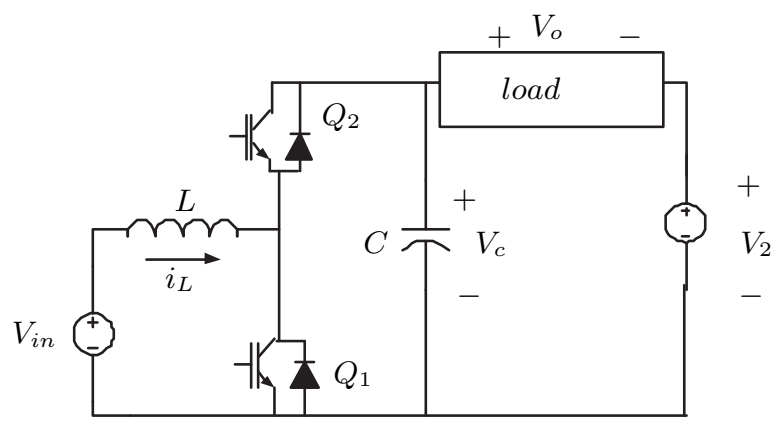

Fig. 4. Simplified boost DC-AC converter.

- all the components are ideal

- the currents and voltages of the converter are continuous

- the load is inductive and resistive

The circuit in Fig. 2 is driven by the transistor ON/OFF inputs $Q_{i}$. This yields two modes of operations illustrated in Fig. 5. For control purposes, it is common to use an averaged model described in terms of the mean currents and voltages values. This model is more suited for control because it is described by a continuous time smooth and nonlinear ODE.

\section{Problem Formulation}

The control problem is to design a control law $u$ by using the Energy Shaping approach showed above. The control law leads the operation modes of each transistor in order to make the output $V_{0}$ to oscillate as a sinusoidal signal with a given amplitude i.e.

$$
\begin{aligned}
V_{0}= & V_{1}-V_{2}=A_{1} \cos \left(\omega t+\varphi_{1}\right)-A_{2} \cos \left(\omega t+\varphi_{2}\right) \\
& =A \cos (\omega t+\varphi)
\end{aligned}
$$

with a pre-specified value for $A_{1}, A_{2}$ and $\omega$. The phase shift $\varphi_{1}$ and $\varphi_{2}$ are no specified. For this reason, the design is completed with an additional outer loop (PLL) that has the function of achieving a phase shift equal to 


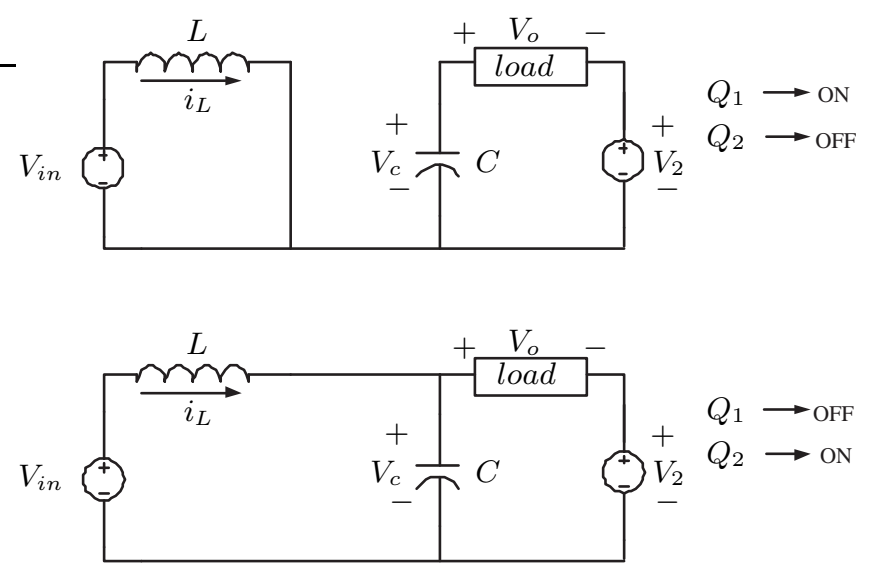

Fig. 5. Operation modes

$180^{\circ}$ between the two voltages $V_{1}$ and $V_{2}$ reaching in that way the desired objective. The design and the application of this PLL for the boost inverter is shown in [9].

The control law was obtained for the case of resistive load in [9]. The aim in this work is to accomplish a control law for boost inverter when the load is not purely resistive by employing of Energy Shaping approach. We consider the case of resistive $(R)$ and inductive $\left(L_{R}\right)$ load.

\section{CONTROL DESIGN FOR INDUCTIVE LOAD}

Figure 6 shows the circuit. Defining the control variable $q$ as $q=0$, when $Q_{1}=O F F$ and $Q_{2}=O N$, and $q=1$, when $Q_{1}=O N$ and $Q_{2}=O F F$, the converter dynamic equations are

$$
\begin{aligned}
L \frac{d i_{L}}{d t} & =-v_{C}+q v_{C_{1}}+V_{i n} \\
C \frac{d v_{C}}{d t} & =i_{L}-q i_{L}-i_{R} \\
L_{R} \frac{d i_{L_{R}}}{d t} & =v_{C}-v_{2}-i_{R} R
\end{aligned}
$$

If $u=1-q$ is taken as the control action on equations (6)-(7), we have

$$
\begin{aligned}
L \frac{d i_{L}}{d t} & =-u v_{C}+V_{i n} \\
C \frac{d v_{C}}{d t} & =u i_{L}-i_{R} \\
L_{R} \frac{d i_{R}}{d t} & =v_{C}-v_{2}-i_{R} R
\end{aligned}
$$

The control law, $u$ can only take two values $u \in\{0,1\}$. Nevertheless, as usual, we consider its average value as we done with currents and voltages and, thus, $u$ is a continuous variable $u \in[0,1]$. Note that it reflects the mean duty-cycle activation percent.

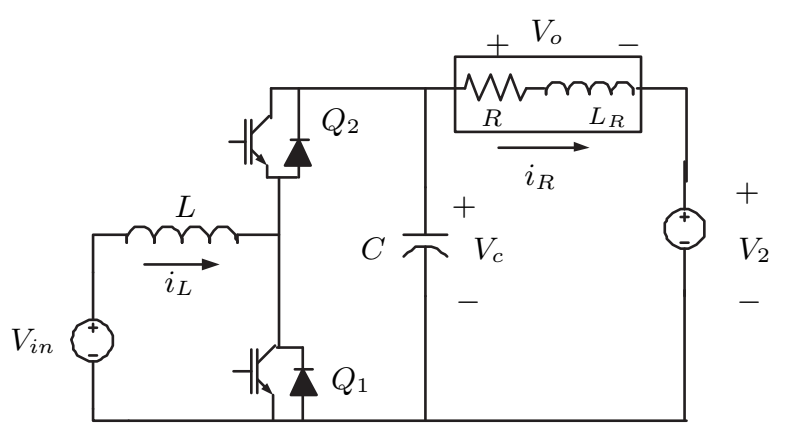

Fig. 6. Simplified boost DC-AC converter with inductive load.

\section{A. Normalized Model}

In order to simplify the study, system (6)-(8) is normalized by using the following change of variables

$$
\begin{aligned}
x_{1} & =\frac{1}{V_{i n}} \sqrt{\frac{L}{C}} i_{L} \\
x_{2} & =\frac{v_{C}}{V_{i n}} \\
x_{4} & =\frac{V_{2}}{V_{i n}} \\
x_{5} & =\frac{1}{V_{i n}} \sqrt{\frac{L_{R}}{C}} i_{R}
\end{aligned}
$$

and defining

$$
\tilde{t}=\omega t
$$

as a new time variable with

$$
\omega_{0}=\frac{1}{\sqrt{L C}}
$$

yielding

$$
\begin{aligned}
& \dot{x}_{1}=-u x_{2}+1 \\
& \dot{x}_{2}=u x_{1}-b x_{5} \\
& \dot{x}_{5}=-c x_{5}+b x_{2}-b x_{4}
\end{aligned}
$$

where $b=\sqrt{\frac{L}{L_{R}}}$ and $c=\frac{R}{L_{R}} \sqrt{L C}$.

Notice that eliminating $u$ in (15)-(16) we obtain

$$
x_{1}\left(1-\dot{x}_{1}\right)=x_{2}\left(\dot{x}_{2}+b x_{5}\right) .
$$

This relationship will be used later.

\section{B. Controller Design}

System (15)-(17) is not directly matchable with system (3)-(4). There are two problems: on one hand the dimension of each system is different, and on the other hand only one degree of freedom $u$ is available. We will treat to match (15)-(16) with (3)-(4) since $x_{1}$ and $x_{2}$ are the states variable of the desired objective curve, and we will use (17) in order to obtain the parameters of the normalized desired currents, $x_{1}$ and $x_{5}$. Another change of variables is needed in order to get that (15)(16) achieves a model structure similar to (3)-(4). For 
this, define

$$
\begin{aligned}
& y_{1}=\frac{x_{1}^{2}+x_{2}^{2}}{2} \\
& y_{2}=x_{1}-b x_{2} x_{5}+y_{20}
\end{aligned}
$$

where $y_{20}$ is an offset term that will be a tuning parameter.

From (19)-(20), it is easy to see that

$$
\begin{aligned}
\dot{y}_{1}= & y_{2}-y_{20} \\
\dot{y}_{2}= & 1+b^{2} x_{5}^{2}-b^{2} x_{2}^{2}+b c x_{5} x_{2}+b^{2} x_{4} x_{2} \\
& -u\left(x_{2}+b x_{1} x_{5}\right)
\end{aligned}
$$

Looking at the target system structure (3)-(4), where the state variables: $\zeta_{1}, \zeta_{2}$, can be identified by the state variables: $y_{1}, y_{2}$, and comparing it with $(21)-(22)$ the choice $k_{a_{1}}=0$ is obvious resulting, as target system

$$
\begin{aligned}
& \dot{y}_{1}=y_{2}-y_{20} \\
& \dot{y}_{2}=-\omega^{2}\left(y_{1}-y_{10}\right)-k \Gamma\left(y_{1}, y_{2}\right)\left(y_{2}-y_{20}\right)
\end{aligned}
$$

where, for simplicity, $k_{a_{2}}$ has been renamed to $k$. This parameter stands for transitory response of the control system.

The control law $u$ that matches (21)-(22) and (23)(24) is

$$
\begin{aligned}
u= & \frac{1+b^{2} x_{5}^{2}-b^{2} x_{2}^{2}-b c x_{5} x_{2}+b^{2} x_{4} x_{2}}{x_{2}+b x_{1} x_{5}} \\
& +\frac{k \Gamma\left(y_{1}, y_{2}\right)\left(y_{2}-y_{20}\right)+\omega^{2}\left(y_{1}-y_{10}\right)}{x_{2}+b x_{1} x_{5}}
\end{aligned}
$$

The ellipse parameters have to be defined as a function of the desired behavior. For this, it is necessary to obtain an analytical expression of the desired objective curve in the plane $x_{1}, x_{2}$. Assume that the desired time evolution for $x_{2}$ is

$$
x_{2}^{*}=A \sin \omega t+B
$$

where $A, B$ and $\omega$ take pre-specified values to obtain the desired evolution for $v_{C}$ and $i_{L}$ using (9)-(12), (13) and (14). Time shift need not to be taken into account. Assume that the desired steady state for $x_{1}$ and $x_{5}$ can be approximated by

$$
\begin{aligned}
& x_{1}^{*}=\alpha_{01}+\alpha_{11} \cos \omega t+\beta_{11} \sin \omega \\
& x_{5}^{*}=\alpha_{03}+\alpha_{13} \cos \omega t+\beta_{13} \sin \omega
\end{aligned}
$$

Substituting (26), (27) and (28) in (18) and (17), neglecting the second order harmonics and equating the bias, $\sin \omega t$ and $\cos \omega t$ the parameters $\alpha_{01}, \alpha_{11}, \beta_{11}, \alpha_{03}$, $\alpha_{13}$ and $\beta_{13}$ can be obtained, as it was shown in [4].

The only question that remains now is to show that the desired behavior for $y_{1}$ and $y_{2}$ is an ellipse and to define the ellipse parameters $\left(\omega, y_{10}, y_{20}\right.$ and $\mu$ ) in terms of the desired behavior for $x_{2}$. For this, we have to obtain the desired evolution for $y_{1}$ and $y_{2}$ applying the change of variables (19)-(20) to (26), (27) and (28)

$$
\begin{aligned}
y_{1}= & \frac{1}{2}\left[\left(\alpha_{01}+\alpha_{11} \sin \omega t+\beta_{11} \cos \omega t\right)^{2}\right. \\
& \left.+(A \sin \omega t+B)^{2}\right] \\
y_{2}= & \alpha_{01}+\alpha_{11} \sin \omega t+\beta_{11} \cos \omega t-b(A \sin \omega t+B) \\
& \left(\alpha_{03}+\alpha_{13} \sin \omega t+\beta_{13} \cos \omega t\right)+y_{20}
\end{aligned}
$$

Expanding these expressions in Fourier terms yield

$y_{1}=y_{1}^{(0)}+y_{1}^{(11)} \cos \omega t+y_{1}^{(12)} \sin \omega t+y_{1}^{(21)} \cos 2 \omega t+y_{1}^{(22)} \sin 2 \omega t$
$y_{2}=y_{2}^{(0)}+y_{2}^{(11)} \cos \omega t+y_{2}^{(12)} \sin \omega t+y_{2}^{(21)} \cos 2 \omega t+y_{2}^{(22)} \sin 2 \omega t$

Equating the terms an expression for the Fourier coefficients can be obtained. Assuming that the double frequency terms, $y_{1}^{(21)}, y_{1}^{(22)}, y_{2}^{(21)}, y_{2}^{(22)}$ can be neglected, these expressions can be approximated by an ellipse in the plane $y_{1}, y_{2}$

$$
\begin{aligned}
\omega y_{1}^{(11)} & =-y_{2}^{(12)} \\
\omega y_{1}^{(12)} & =y_{2}^{(11)}
\end{aligned}
$$

Using the expressions previously obtained for $\alpha_{01}, \alpha_{11}$, $\beta_{11}, \alpha_{03}, \alpha_{13}$ and $\beta_{13}$ the parameters of this ellipse are given by

$$
\begin{aligned}
y_{10} & =y_{1}^{(0)} \\
y_{20} & =y_{2}^{(0)} \\
\mu & =\omega^{2}\left(\left(y_{1}^{(11)}\right)^{2}+\left(y_{1}^{(12)}\right)^{2}\right)
\end{aligned}
$$

\section{Control Law for the Full Converter}

In this section the previous control law is extrapolated to consider that the boost inverter is composed of two DC-DC converters and, thus, it has two control signals. The model of the system is

$$
\begin{aligned}
L_{1} \frac{d i_{L_{1}}}{d t} & =-u_{1} v_{C_{1}}+V_{i n} \\
C_{1} \frac{d v_{c_{1}}}{d t} & =u_{1} i_{L_{1}}-i_{R} \\
L_{2} \frac{d i_{L_{2}}}{d t} & =-u_{2} v_{C_{2}}+V_{i n} \\
C_{2} \frac{d v_{c_{2}}}{d t} & =u_{2} i_{L_{2}}+i_{R} \\
L_{R} \frac{d i_{R}}{d t} & =v_{C 1}-v_{C_{2}}-i_{R} R
\end{aligned}
$$

Assume that $C=C_{1}=C_{2}$ and $L=L_{1}=L_{2}$.

By comparison of systems (34)-(38) and (6)-(8) we can notice a similar structure for the pairs of current and voltage of both boost DC-DC converters. Therefore, the two control laws are easy to be obtained. The first control law $u_{1}$ is the same expression as (25)and the control law 
$u_{2}$ is obtained by symmetry.

$$
\begin{aligned}
u_{1}= & \frac{1+b^{2} x_{5}^{2}-b^{2} x_{2}^{2}+b c x_{5} x_{2}+b^{2} x_{4} x_{2}}{x_{2}+b x_{1} x_{5}} \\
& +\frac{k \Gamma\left(y_{1}, y_{2}\right)\left(y_{2}-y_{20}\right)+\omega^{2}\left(y_{1}-y_{10}\right)}{x_{2}+b x_{1} x_{5}} \\
u_{2}= & \frac{1+b^{2} x_{5}^{2}-b^{2} x_{4}^{2}-b c x_{5} x_{4}+b^{2} x_{4} x_{2}}{x_{4}-b x_{3} x_{5}} \\
& +\frac{k \Gamma\left(y_{3}, y_{4}\right)\left(y_{4}-y_{40}\right)+\omega^{2}\left(y_{3}-y_{30}\right)}{x_{4}-b x_{3} x_{5}}
\end{aligned}
$$

\section{Simulation Results}

The following simulations are made considering $V_{\text {in }}=$ $20 \mathrm{~V}, R=100 \Omega, L=1.5 \mathrm{mH}, C=100 \mu F, L_{R}=15 \mathrm{mH}$. The desired output of the circuit is $V_{\text {out }}=40 \sin 50 t \mathrm{~V}$.

$L$ and $C$ have been chosen following some rules [12], [13] that pursue the next goals

1) small ripple in currents and voltages

2) bounded impedance current

3) fulfilment of control signal saturation limits

In this case, as the DC-DC converter voltages must have a phase shift of $180^{\circ}$ the normalized desired voltages are

$$
\begin{aligned}
& x_{2}^{*}=A \sin \omega t+B \\
& x_{4}^{*}=-A \sin \omega t+B
\end{aligned}
$$

Parameter $A$ has to be the half of the desired output voltage amplitude and $B$ is chosen, so that, $x_{2}$ and $x_{4}$ are always positive. In order to obtain this voltage, the parameters are $A=1$ and $B=5$ with $\omega=0.121$ in the normalized variables $x_{1}, x_{2}$.

The ellipse parameters, using the previous development, result $y_{10}=y_{30}=12.842, \mu_{1}=\mu_{2}=0.37$. On the other hand, the tuning parameters are chosen as $k=1.2$ and for simplicity, we chose $y_{20}=0, y_{40}=0$.

The desired currents are:

$$
\begin{aligned}
& x_{1}^{*}=0.04+0.616 \cos \omega t+0.4 \sin \omega t \\
& x_{3}^{*}=0.04-0.616 \cos \omega t-0.4 \sin \omega t \\
& x_{5}^{*}=-0.0125 \cos \omega t+0.4 \sin \omega t
\end{aligned}
$$

Note, that the currents associated with $x_{1}$ and $x_{3}$ are not sinusoidal waves, that is due to nonlinear nature of the circuit.

As was said above, we will use the PLL designed in [9] to synchronize the voltages $V_{1}$ and $V_{2}$.

Figure 7 shows the results of a simulation using a sample time of 0.001s. Both dc-dc converters achieve the desired limit cycle. Note that the steady-state behavior does not correspond to a perfect ellipse due to the system nonlinearities.

In Fig. 8 the boost inverter output voltage is represented. This voltage signal is compared with the desired boost inverter output, getting an excellent result.
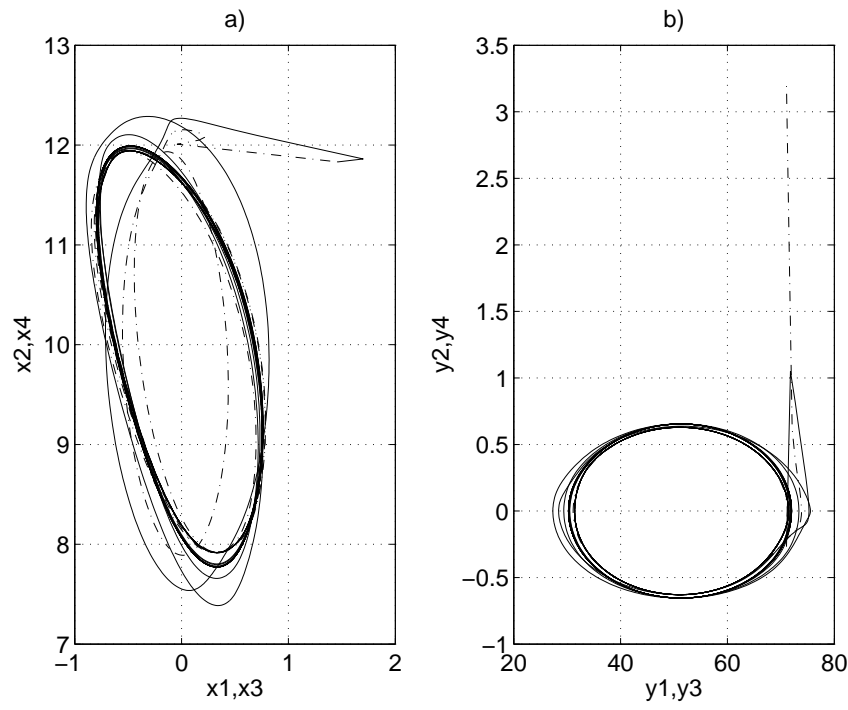

Fig. 7. a) State spaces $\left(x_{1}, x_{2}\right)$ (solid) and $\left(x_{3}, x_{4}\right)$ (dashed); b) state spaces $\left(y_{1}, y_{2}\right)$ (solid) and $\left(y_{3}, y_{4}\right)$ (dashed) with inductive load

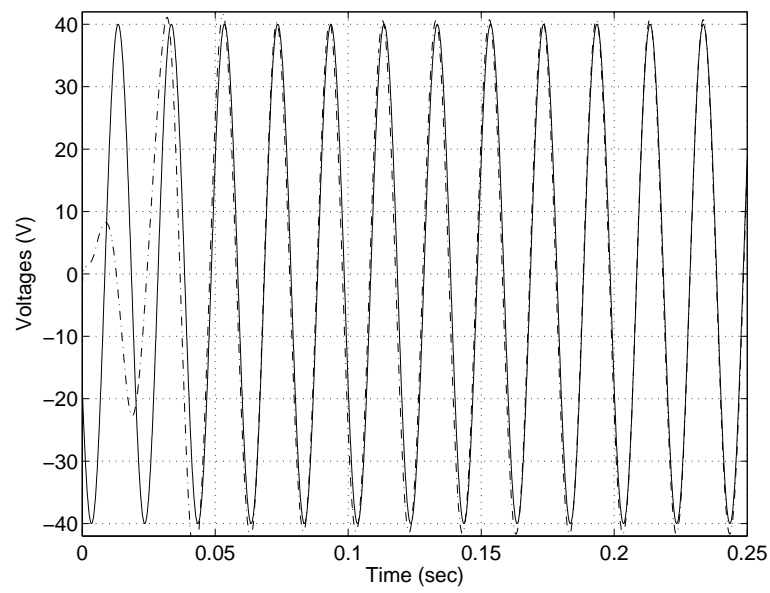

Fig. 8. Desired (solid) and simulated (dashed) output voltage with inductive load

\section{E. Synchronizing with the Electrical Network}

The boost inverter output signal can be synchronized with the network voltage by mean of two PLLs, as it was sawn in [4]. One of voltage of a DC-DC converter is synchronized with the network voltage without phase shift, while the another voltage of the other DC-DC converter is synchronized with the network voltage with a phase shift of $180^{\circ}$.

In this paper, we see as a boost inverter with inductive and resistive load is synchronized with the network voltage.

The performance of the synchronization of the boost DC-AC converter with the electrical supply voltage when the converter has a inductive and resistive load is represented in Fig.9. The inverter parameters values chosen for simulation are: $V_{i n}=48 \mathrm{~V}, R=100 \Omega, L=250 \mu \mathrm{H}$, $C=250 \mu F, L_{R}=10 \mathrm{mH}$. The desired frequency and 
voltage amplitude is $V_{\text {out }}=325 \sin 50 t \mathrm{~V}$. In order to get such voltage amplitude the parameters of $x_{2}^{*}$ and $x_{4}^{*}$ were $A=3.385$ and $B=12.5$ with $\omega=0.0785$.

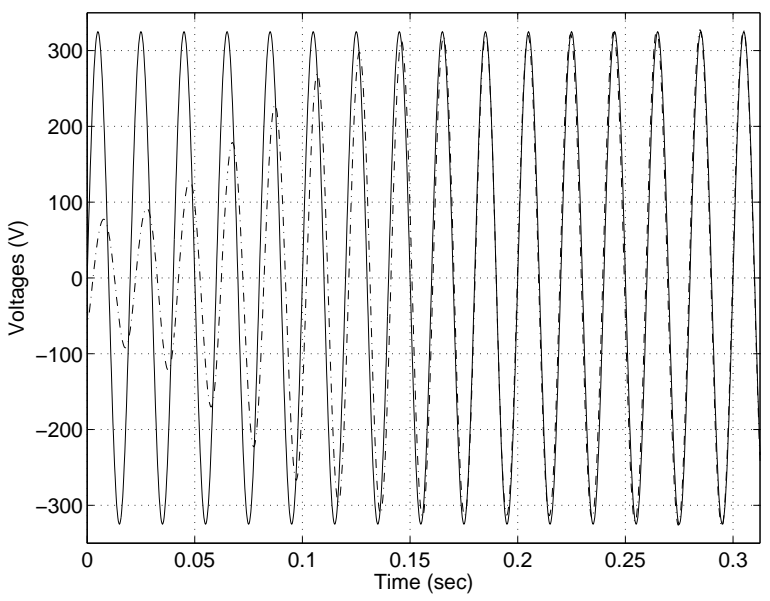

Fig. 9. Electrical supply voltage (solid) and simulated output voltage synchronized with inductive load(dashed).

\section{Conclusions}

This paper presents a control strategy for the boost DC-AC converter with RL load. The method is based on Energy Shaping by means of generation of a limit cycle and does not need the introduction of time-dependent reference signals. It is shown that the resultant controller achieves the objective provided that a phase locked loop is added. The same idea has been used in order to solve the problem of network synchronization. The results are tested by simulations.

Open problems are the consideration of unknown loads as well as the case of capacitive loads.

\section{Acknowledgments}

This research has been supported by the MEC-FEDER grant DPI2006-07338.

\section{REFERENCES}

[1] R. O. Cáceres and I. Barbi, "A boost DC-AC converter: analysis, design, and experimentation," in IEEE Transactions on Power Electronics, vol. 14, 1999, pp. 134-141.

[2] N. Vázquez, D. Cotés, C. Hernández, J. Álvarez, J. Arau, and J. Álvarez, "A new nonlinear control strategy for the boost inverter," in Proceedings of the $34^{\text {th }}$ Power Electronics Specialist Conference of the IEEE, PESC03, Acapulco, Mexico, 2003.

[3] P. Sanchís, A. Ursaea, E. Gubia, and L. Marroyo, "Boost dcac inverter: a new control strategy," in Transactions on Power Electronics, IEEE, vol. 20, 2005, pp. 343-353.

[4] F. Gordillo, D. Pagano, and J. Aracil, "Autonomous oscillation generation in electronic converters," in Proceedings of the 2004 International Workshop on Electronics and System Analysis, IWESA'04, 2004, pp. 57-65.

[5] J. Aracil, F. Gordillo, and J. Acosta, "Stabilization of oscillations in the inverted pendulum," in XV IFAC World Congress, 2002.

[6] F. Gómez-Estern, J. Aracil, and F. Gordillo, "The Hopf bifurcation and controlled oscillations in electromechanical systems," in Proceedings of the MED'02, Lisbon, Portugal, 2002.
[7] F. Gordillo, J. Aracil, and F. Gómez-Estern, "Stabilization of autonomous oscillations and the Hopf bifurcation in the ball and beam," in Proceedings of the CDC'02, vol. 4, Las Vegas, USA, 2002, pp. 3924-3925.

[8] J. Aracil and F. Gordillo, "On the control of oscillations in DCAC converters," in Proceedings of the $28^{\text {th }}$ Annual Conference of the IEEE Industrial Electronics Society, Sevilla, Spain, 2002.

[9] C. Albea, F. Gordillo, and J. Aracil, "Control of the boost dc-ac converter by energy shaping," in Proceedings of the $32^{\text {th }}$ Annual Conference of the IEEE Industrial Electronics Society, vol. 32, Paris,France, 2006, pp. 754-759.

[10] C. Albea, C. C. de Wit, and F. Gordillo, "Adaptive control of the boost dc-ac converter," in Submitted to the 2007 IEEE Multi-conference on Systems and Control (MSC), 2007.

[11] R. Griño, R. Costa-Castelló, and E. Fossas, "Digital control of a single-phase shunt active filter," in Proceedings of the $35^{\text {th }}$ Power Electronics Specialist Conference of the IEEE, PESC04, vol. 5, Aachen, German, 2004, pp. 3994-3998.

[12] D. Cortés, "Generación de voltajes de corriente alterna mediante convertidores," Ph.D. dissertation, CICESE, 2006.

[13] D. Cotés, A. L. Fradkov, and J. Álvarez, "Tracking on the boost converter using standard regulation techiniques," in Proceedings of the American Control Conference of the IEEE, ACC01, Arlington VA, USA, 2001. 